\title{
Biosorption of macronutrients by Brazilian tropical peats
}

\section{Camila Almeida Melo, Lílian Karla de Oliveira, Leonardo Fernandes Fraceto \& André Henrique Rosa}

To cite this article: Camila Almeida Melo, Lílian Karla de Oliveira, Leonardo Fernandes Fraceto \& André Henrique Rosa (2018) Biosorption of macronutrients by Brazilian tropical peats, Communications in Soil Science and Plant Analysis, 49:12, 1530-1539, DOI:

10.1080/00103624.2018.1474474

To link to this article: https://doi.org/10.1080/00103624.2018.1474474

曲 Published online: 21 May 2018.

Submit your article to this journal $\pi$

山 Article views: 34

View Crossmark data ¿ 


\title{
Biosorption of macronutrients by Brazilian tropical peats
}

\author{
Camila Almeida Melo, Lílian Karla de Oliveira, Leonardo Fernandes Fraceto, \\ and André Henrique Rosa
}

Departamento de Engenharia Ambiental, Grupo de Estudos Ambientais, UNESP, Univ Estadual Paulista, Sorocaba, São Paulo State, Brazil

\begin{abstract}
The objective of this work was to evaluate the adsorption of macronutrients calcium, potassium, magnesium, nitrogen, and phosphorus in two Brazilian tropical peat samples, investigating the effect of $\mathrm{pH}$ and determining the kinetics of the adsorption process. Two different Brazilian tropical peat samples were characterized using FTIR, TG, and SEM techniques. Different $\mathrm{pH}$ conditions were tested, as well as different mass concentrations of the peats. Differences in the chemical structures of the peat samples directly influenced the adsorptive capacities for the macronutrients. The adsorptive capacity for nitrogen was highest at $\mathrm{pH} 3$, while the best adsorption of calcium and potassium was obtained at $\mathrm{pH} 6$. The best fit to the data was provided by the pseudo-second-order model, which confirmed the rapid adsorption of calcium by both peats.
\end{abstract}

\section{ARTICLE HISTORY}

Received 16 November 2015

Accepted 1 May 2018

\section{KEYWORDS}

Adsorption; kinetics; macronutrients; tropical peat

\section{Introduction}

The need to produce food to sustain the growing global population, at low cost and without causing serious environmental impacts, has stimulated research in many different areas. One way of reducing the energy consumption and impacts associated with food production is to combine, in a single fertilizer, both the essential nutrients and the organic matter that are fundamental for plant growth.

Biosorption can be defined as a physicochemical process that occurs naturally in a biomass and enables the binding and/or passive concentration of chemical species such as cations or anions (Gadd 2009). Biosorption has been widely studied in remediation processes, since it offers the advantage of being able to transfer a contaminant to an adsorbent material in a natural fashion, avoiding high expenditure on energy (Zenteno et al. 2013; Kamari, Pulford, and Hargreaves 2011). A wide variety of adsorbent materials have been used, ranging from agricultural waste biomass (Garg et al. 2008) to compounds naturally present in nature, such as humic substances (Perminova and Hatfield 2005).

Peats are defined as a heterogeneous mixture of decomposing plant material and are normally formed in flooded environments (Moore 1989). Their special characteristic is a high content of organic matter, which can comprise up to $90 \%$ of the mass of the material. The presence of this organic matter provides peats with the capacity to adsorb both cationic and anionic species, including the macronutrients calcium $(\mathrm{Ca})$, potassium $(\mathrm{K})$, magnesium $(\mathrm{Mg})$, nitrogen $(\mathrm{N})$, and phosphorus $(\mathrm{P})$. Peats can, therefore, be a good alternative for use as fertilizers, providing a combination of organic matter and essential nutrients. Peats have been investigated for use as in natura organic fertilizers (Kiehl 1985) and as adsorbents in systems for environmental decontamination (Al-Faqih, Johnson, and Allen 2008; Novoselova and Sirotkina 2008). 
The objective of this work was to determine the best conditions for adsorption of the macronutrients calcium, potassium, magnesium, nitrogen, and phosphorus by samples of in natura tropical peats, as well as to identify the type of kinetics involved in the adsorption, envisaging the possible application of enriched peats in agriculture.

\section{Materials and methods}

\section{Sampling and characterization of peat}

The peat samples were collected in February 2011 from two peatlands located in the State of Sergipe, Brazil, at Santo Amaro das Brotas (TSA; 36 58 $52^{\prime \prime}$ W; 10 $49^{\prime} 3^{\prime \prime}$ ) and Serra de Itabaiana (TSI; $\left.37^{\circ} 20^{\prime} 25^{\prime \prime} \mathrm{W} ; 10^{\circ} 45^{\prime} 29^{\prime \prime} \mathrm{S}\right)$. Compound samples $(\mathrm{n}=5)$ were obtained at a depth of $20 \mathrm{~cm}$ and stored in polyethylene bags before drying, grinding and homogenizing in a porcelain mortar, and sieving through a $2 \mathrm{~mm}$ mesh.

The TSA and TSI peat samples were characterized by infrared spectroscopy (FTIR), thermogravimetry (TG), and scanning electron microscopy (SEM). The FTIR spectra were obtained using a Varian 660-IR instrument (Varian, Inc., Palo Alto, CA), in the spectral region from 4000 to $400 \mathrm{~cm}^{-1}$. The measurements employed pastilles composed of peat and $\mathrm{KBr}$, in a 1:10 ratio, with 32 scans and a resolution of $4 \mathrm{~cm}^{-1}$. The TG analyses were performed using a TA Instruments thermal analyzer (Model SDT 2960, TA Instruments, New Castle, DE) equipped with an alumina support and operated using a temperature ramp of $10^{\circ} \mathrm{C} \min ^{-1}$ up to $1000^{\circ} \mathrm{C}$, under an atmosphere of synthetic air. SEM analysis (Model JSM-6700F, JEOL, Tokyo, Japan) was used to determine the surface morphology of the peat samples. Prior to the acquisition of the electron micrographs, the previously dried samples were fixed onto metallic supports (stubs) using double-sided tape and coated with a layer of gold for 150 seconds at a current of $25 \mathrm{~mA}$.

\section{Chemicals and reagents}

The biosorption experiments were performed using the macronutrients nitrogen (ammonia), phosphorus, potassium, calcium, and magnesium. Stock $500 \mathrm{mg} \mathrm{L}^{-1}$ solutions were prepared using the compounds ammonium chloride $\left(\mathrm{NH}_{4} \mathrm{Cl}\right)$, monopotassium phosphate $\left(\mathrm{KH}_{2} \mathrm{PO}_{4}\right)$, potassium chloride $(\mathrm{KCl})$, calcium chloride $\left(\mathrm{CaCl}_{2}\right)$, and magnesium chloride $\left(\mathrm{MgCl}_{2}\right)$ (Synth, $>95 \%$ purity). All the solutions, including standards and dilutions, were prepared using deionized water (Milli-Q Plus, Millipore, Darmstadt, Germany).

\section{Equilibrium time of biosorption}

Firstly, the time taken to reach equilibrium was evaluated. For this, the macronutrients were added (using a multi-element standard solution) to beakers containing $300 \mathrm{~mL}$ of deionized water, to give final concentrations of $10.0 \mathrm{mg} \mathrm{L}^{-1}$. Subsequently, a mass of $1.0 \mathrm{~g}$ of each peat (TSA or TSI) was added (separately) to the beakers and the mixture was maintained under agitation on a horizontal shaker at ambient temperature $\left(25 \pm 1^{\circ} \mathrm{C}\right)$. At predetermined intervals $(0,10,30,60,120,240,1440$, 2880, and 4380 minutes), $5 \mathrm{~mL}$ aliquots were removed, centrifuged, and analyzed.

\section{Biosorption of macronutrients}

The biosorption process is governed by factors that include the $\mathrm{pH}$ of the medium and the mass of the adsorbent material (Gadd 2009). The best values of these parameters were determined by adding the macronutrients to final concentrations of $10.0 \mathrm{mg} \mathrm{L}^{-1}$ (using a multi-element standard solution) in beakers containing $300 \mathrm{~mL}$ of deionized water. Different masses $(0.5,1.0,2.0$, and $4.0 \mathrm{~g})$ of peats TSA and TSI were transferred individually to the beakers, and the mixtures were maintained under 
agitation at ambient temperature. After allowing sufficient time to reach equilibrium, $5 \mathrm{~mL}$ aliquots were withdrawn, centrifuged, and analyzed.

The effect of the $\mathrm{pH}$ of the medium was evaluated in batch experiments, with the macronutrients added to final concentrations of $10.0 \mathrm{mg} \mathrm{L}^{-1}$ (as described above). The optimum mass of peat samples TSA and TSI (determined in the preceding experiments) was then added to the beakers, and the $\mathrm{pH}$ was adjusted to values of $3.0,4.5$, or 6.0 using $6.0 \mathrm{~mol} \mathrm{~L}^{-1}$ solutions of hydrochloric acid $(\mathrm{HCl})$ or sodium hydroxide $(\mathrm{NaOH})$. After allowing time to reach equilibrium, $5 \mathrm{~mL}$ aliquots were withdrawn, centrifuged, and analyzed. The experiments were performed in triplicate at each $\mathrm{pH}$ value.

The adsorptive capacity of the peat samples for the macronutrients was calculated using

$$
\mathrm{q}_{\mathrm{eq}}=\frac{\mathrm{V}(\text { cfinal }- \text { cinitial })}{\text { Mass }}
$$

where $V$ is the volume used in the experiment, Cfinal is the concentration at equilibrium, Cinitial is the concentration prior to addition of the adsorbent, and Mass is the mass of adsorbent employed.

Once the best $\mathrm{pH}$ for the biosorption had been established, the corresponding experimental data were used to determine the adsorption kinetics. The pseudo-first order (Eq. 2) and pseudo-second-order (Eq. 3) kinetic models were applied, with linearized plots of $1 / \mathrm{q}_{\mathrm{t}}$ against $1 / \mathrm{t}$, and $\mathrm{t} / \mathrm{q}_{\mathrm{t}}$ against $\mathrm{t}$, providing the values of the first order $\left(\mathrm{k}_{1}\right)$ and second order $\left(\mathrm{k}_{2}\right)$ rate constants, respectively, as well as the values of $\mathrm{q}_{\mathrm{eq}}$ (the quantity of macronutrient adsorbed at equilibrium). The pseudo-first order kinetic model is applicable when the adsorption rate is proportional to the number of available active sites (Eq. 2) (Liu \& Wang, 2009). The pseudo-second-order model considers chemical adsorption involving the solid adsorbent and solute, with the sharing of electrons between the atoms of the adsorbed species and the surface of the solid material (Eq. 3) (Ho and McKay 2000).

$$
\begin{gathered}
\frac{1}{\mathrm{q}_{\mathrm{t}}}=\frac{\mathrm{k}_{1}}{\mathrm{q}_{\mathrm{eq}}} \frac{1}{\mathrm{t}}+\frac{1}{\mathrm{q}_{\mathrm{eq}}} \\
\frac{\mathrm{t}}{\mathrm{q}_{\mathrm{t}}}=\frac{1}{\mathrm{k}_{2} \times \mathrm{q}_{\mathrm{eq}}{ }^{2}}+\frac{\mathrm{t}}{\mathrm{q}_{\mathrm{eq}}}
\end{gathered}
$$

In the above equations, $\mathrm{k}_{1}\left(\mathrm{~min}^{-1}\right)$ is the pseudo-first order rate constant, $\mathrm{k}_{2}\left(\mathrm{~g} \mathrm{mg}^{-1} \mathrm{~min}^{-1}\right)$ is the pseudo-second-order rate constant, $\mathrm{t}(\mathrm{min})$ is the adsorption time, and $\mathrm{q}_{\mathrm{eq}}$ and $\mathrm{q}_{\mathrm{t}}\left(\mathrm{mg} \mathrm{g}^{-1}\right)$ are the quantities of macronutrient adsorbed at equilibrium and at time $t$, respectively.

\section{Chemical analysis}

The concentrations of calcium, potassium, and magnesium were determined by atomic emission spectroscopy (ICP-OES), using an Agilent-700A instrument (Agilent Inc., Santa Clara, CA) fitted with a "seaspray" type nebulizer and operated at a radiofrequency power of $1.0 \mathrm{~kW}$, with a plasma argon flow of $15.0 \mathrm{~L} \mathrm{~min}^{-1}$ and a nebulizer pressure of $200 \mathrm{kPa}$. The concentrations of nitrogen (ammonia) and phosphorus were determined using spectrophotometric methods employing salicylic acid and vanadomolybdophosphoric acid, respectively (Clesceri et al. 1998). The limits of detection were $0.1 \mathrm{mg} \mathrm{L}^{-1}$ (nitrogen), $0.04 \mathrm{mg} \mathrm{L}^{-1}$ (phosphorus), $0.2 \mathrm{mg} \mathrm{L}^{-1}$ (potassium), $0.3 \mathrm{mg} \mathrm{L}^{-1}$ (calcium), and $0.03 \mathrm{mg} \mathrm{L}^{-1}$ (magnesium), calculated from the standard deviations of ten readings of analytical blanks and the angular coefficients of the analytical curves (MacNaught et al., 1997).

\section{Results and discussion}

\section{Infrared spectroscopy, thermogravimetry, and scanning electron microscopy}

Figure 1A illustrates the FTIR spectra obtained for the two different peat samples, which showed the characteristic broad bands of samples rich in organic matter, due to the overlap of individual absorption 


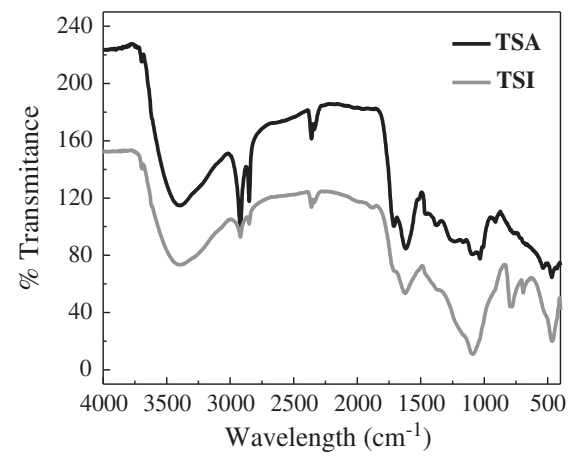

(a)

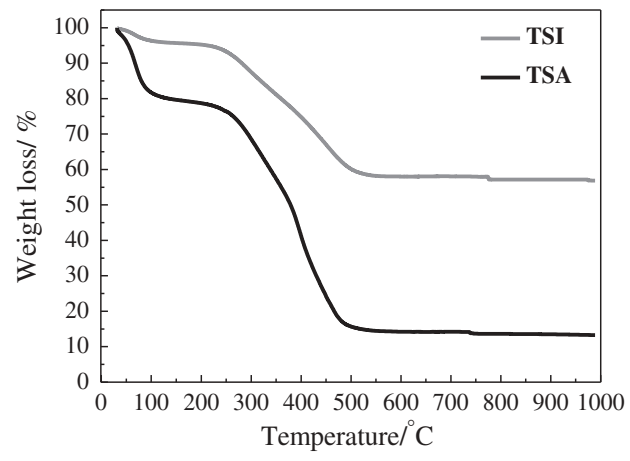

(b)

Figure 1. Infrared spectra (a) and thermogravimetry curves (b) for the peat samples TSA and TSI.

bands. Both spectra showed a broad intense band close to $3500 \mathrm{~cm}^{-1}$, attributed to stretching of the O-H bond of carboxylic, phenolic, and alcohol groups. Two discrete bands at 2910 and $2840 \mathrm{~cm}^{-1}$ were associated with C-H stretching of aliphatic carbons. A discrete peak at a wavelength of $1710 \mathrm{~cm}^{-1}$, which was only observed for the TSA sample, was due to stretching of the $\mathrm{C}=\mathrm{O}$ bond of aldehyde, ketone, and carboxylic acid groups. Both peat samples presented an intense band at $1620 \mathrm{~cm}^{-1}$, associated with aromatic ring $\mathrm{C}=\mathrm{C}$ stretching. Only sample TSI showed an intense broadband at $1100 \mathrm{~cm}^{-1}$, related to vibration of the $\mathrm{C}-\mathrm{O}$ bond of alcohols. A peak at $782 \mathrm{~cm}^{-1}$, which was also only observed for the TSI sample, was indicative of the stretching of Si-O groups, reflecting the presence of inorganic material such as the silicates commonly found in sands.

It could be concluded from the infrared spectra that the TSA sample presented a chemical structure rich in aromatic compounds containing substituent functional groups including aldehyde, ketone, and carboxylic acid species. The TSI sample possessed a chemical structure containing aromatic compounds with preferential alcohol groupings, together with a silicon component. Melo et al. (2014) used the tropical peat samples from the same locations here in this work and characterized them using elemental analysis and nuclear magnetic resonance of ${ }^{13} \mathrm{C}$ and concluded that the TSA sample has a higher aromaticity and phenolic compounds than TSI sample.

Figure 1B shows the thermogravimetric curves obtained for the two peat samples. In both cases, there were three phases of mass loss during decomposition of the organic matter. The first occurred at $30-150^{\circ} \mathrm{C}$ and corresponded to the evaporation of water. The second and third phases occurred at temperatures of $150-350^{\circ} \mathrm{C}$ and $350-550^{\circ} \mathrm{C}$, respectively. At these temperatures, there can be losses of polar functional groups such as phenolic $\mathrm{OH}$ and $\mathrm{COOH}$, as well as combustion of aliphatic structures (Schnitze and Hoffman 1965). Campanella, Tomassetti, and Piccolo (1990) also evaluated thermogravimetric curves, and identified decarboxylation and the loss of unsaturates at a temperature of around $280^{\circ} \mathrm{C}$. At temperatures above $500^{\circ} \mathrm{C}$, losses have been associated with the depletion of aromatic structures (Trompowsky et al. 2005).

The calculated mass losses are provided in Table 1 . During the first phase $\left(30-150^{\circ} \mathrm{C}\right)$, there were mass losses of $20 \%$ for TSA and $4 \%$ for TSI. During the second phase $\left(150-350^{\circ} \mathrm{C}\right)$, both TSA and TSI showed greater mass losses, of $45 \%$ and $19 \%$, respectively. In the third phase $\left(350-550^{\circ} \mathrm{C}\right)$, the losses were $85 \%$ for TSA and $42 \%$ for TSI. From these percentage mass losses, it could be concluded that the TSA sample possessed a greater quantity of structures with phenolic and carboxylic groups, as well as a higher content

Table 1. Weight losses (\%) for peat samples TSA and TSI during different decomposition stages.

\begin{tabular}{lcccc}
\hline & $30-150^{\circ} \mathrm{C}$ & $150-350^{\circ} \mathrm{C}$ & $350-550^{\circ} \mathrm{C}$ & Up to $850^{\circ} \mathrm{C}$ \\
\hline TSA & 20.5 & 24.5 & 40.0 & 2.0 \\
TSI & 4.4 & 14.0 & 23.0 & 2.0 \\
\hline
\end{tabular}


of aromatic compounds, compared to the TSI sample. It should be pointed out that the mass loss percentages given in Table 1 consider the mass at the start of each phase to be $100 \%$.

Figure 2 shows SEM micrographs of the two peat samples. Differences can be seen in both the size and form of the pores. In the case of sample TSA, the pores were larger and aggregates of organic matter were present, which could favor the adsorption of metallic macronutrient species. The pores of the TSI sample were smaller, and structures such as fibers indicated the presence of minerals.

\section{Adsorption conditions}

The time taken to reach equilibrium can vary according to the type of adsorbent material, as well as the metallic species employed in the adsorption experiments (Soares, Casagrande, and Mouta 2009). It was found that for both peat samples and all the macronutrients, adsorption reached a maximum, without any further significant variations in concentrations, within 1440 minutes (Figure 3). Wahab, Jellali, and Jedidi (2010) investigated the interaction of the ammonium ion with sawdust samples and found that equilibrium was reached in 20 minutes, which was faster than the equilibrium time of 120 minutes reported for zeolite samples (Ji, Yuan, and Li 2007; Wu et al. 2006). This behavior was attributed to the fact that the lignocellulosic surface of sawdust possesses negative charges that can provide a more rapid interaction with the ammonium ion. In the present work, however, the observed equilibrium times were much longer, compared to the earlier studies. An explanation for this could be the high level of competition in a medium containing all the macronutrients together in the same solution.

The results of the experiments to determine the effect of different masses $(0.5,1.0,2.0$, and $4.0 \mathrm{~g})$ of the peats on the macronutrient adsorption capacities are illustrated in Figure 4. Saturation occurred at a mass of $2.0 \mathrm{~g}$, for which the adsorption was the same as that achieved using a mass of $4.0 \mathrm{~g}$. In earlier work,
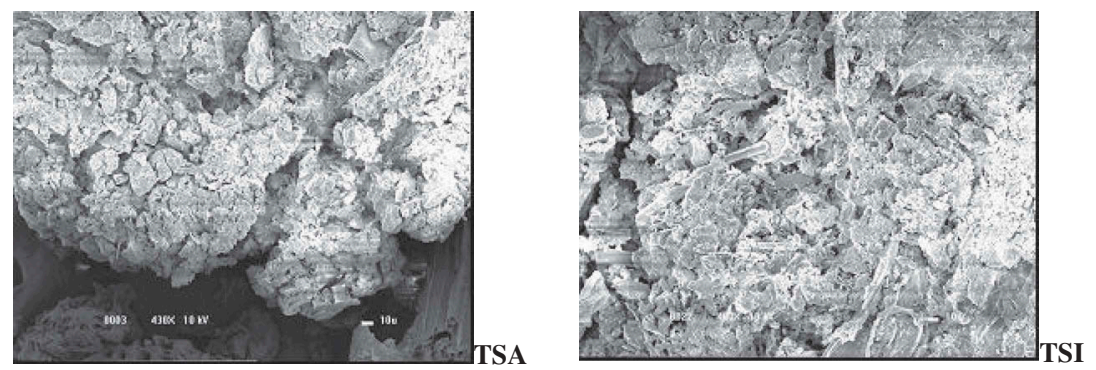

Figure 2. Scanning electron microscopy of peat samples TSA and TSI.
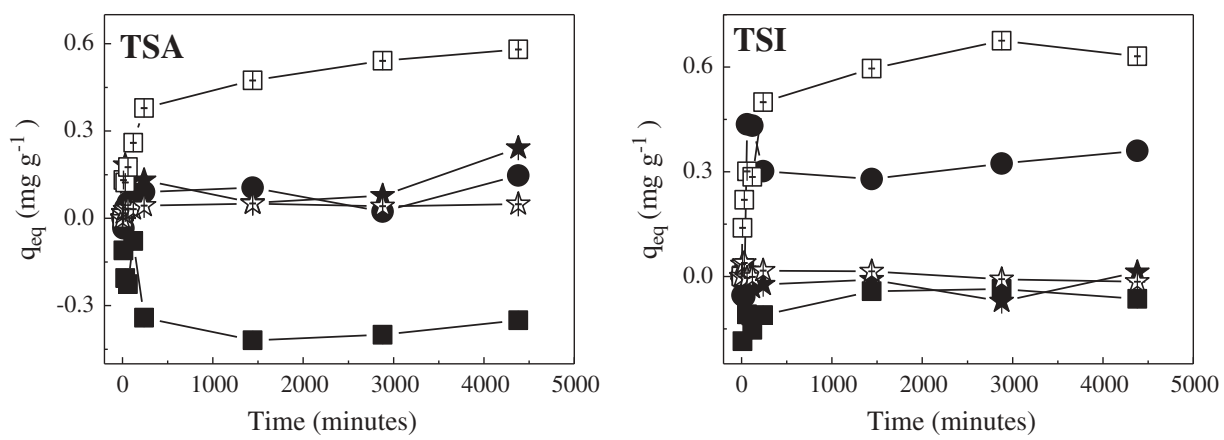

Figure 3. Adsorption of the macronutrients nitrogen $(\square)$, calcium $(\square)$, potassium $(\bullet)$, phosphorus $(\square)$, and magnesium $\left(^{*}\right)$ by peat samples TSA and TSI. 

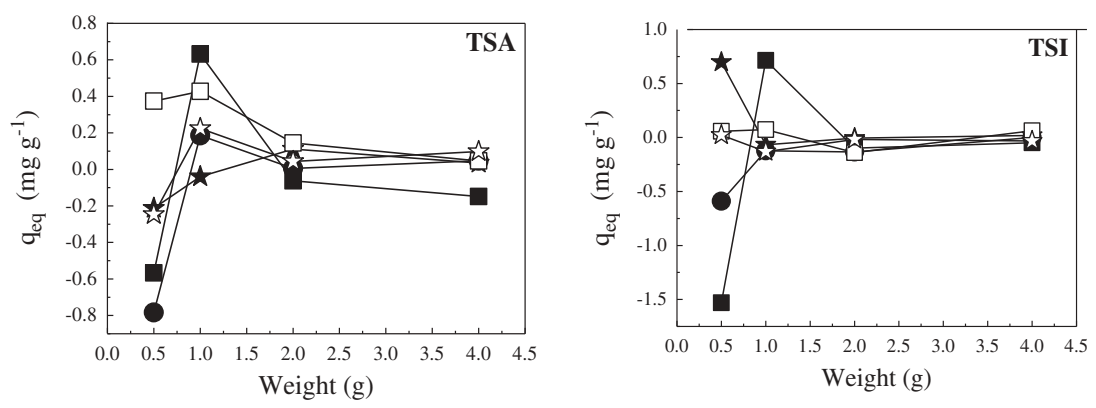

Figure 4. Adsorptive capacities of different masses of peat samples TSA and TSI for the macronutrients nitrogen potassium $(\bullet)$, phosphorus $(\square)$, and magnesium $(*)$.

Goveia et al. (2013) investigated the effect of the mass of humin on the adsorption of micronutrients and obtained similar results, with maximum adsorption for a mass of $2.0 \mathrm{~g}$, with no further improvement when $4.0 \mathrm{~g}$ of humin was used. It is therefore important to determine the smallest amount of adsorbent acquired to achieve maximum macronutrient adsorption, in order to ensure efficient utilization of the material.

The influence of $\mathrm{pH}$ on adsorption is well known since it directly affects activation of the active sites of the adsorbent material, which are either protonated or ionized. In the case of materials such as peats, it is especially important to determine the $\mathrm{pH}$ at which adsorption of the macronutrients is optimized, because peat contains a high level of organic matter including naturally acidic species such as carboxylic $(-\mathrm{COOH})$ and phenolic $(-\mathrm{OH})$ groups (as confirmed here in the characterization analyses). These species are able to interact in different ways with other compounds that are weakly or strongly acidic or basic (De Moraes Sa et al. 2009). The presence of nitrogen-containing species $(-\mathrm{NH})$ can also affect the adsorption process because, depending on the $\mathrm{pH}$ of the medium, they can become protonated and able to interact with other anionic compounds.

The effect of $\mathrm{pH}$ on the adsorption of the macronutrients by peat samples TSA and TSI is illustrated in Figure 5. It can be seen that as the $\mathrm{pH}$ was increased, there was an increase in the capacity of both peats to adsorb calcium and potassium, for which adsorption was greatest at $\mathrm{pH}$ 6. This behavior was as expected for peat samples, since the active sites containing acidic groups are negatively ionized, and can therefore interact with cationic species. In contrast, the macronutrient phosphorus showed no adsorption by either peat at any $\mathrm{pH}$ value. This finding could be explained by the characteristic chemical structures of the samples. The presence of nitrogenated compounds that might be able to interact with phosphorus was not identified in the infrared spectra. Phosphorus was present in anionic form $\left(\right.$ as $\left.\mathrm{H}_{2} \mathrm{PO}_{4}{ }^{-}\right)$throughout
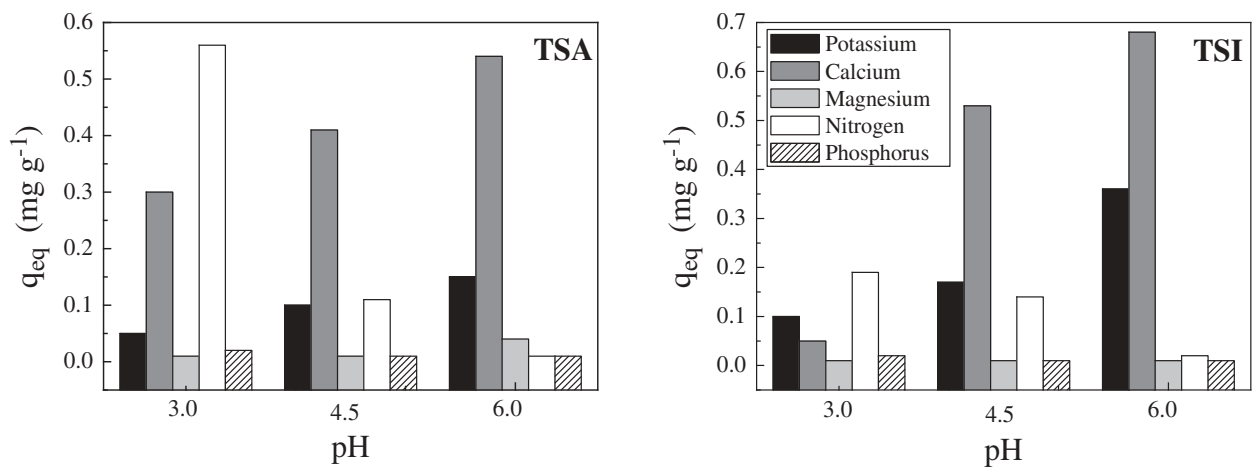

Figure 5. Adsorptive capacities of peat samples TSA and TSI for the macronutrients nitrogen, phosphorus, potassium, magnesium, and calcium, at three different $\mathrm{pH}$ values. 
the $\mathrm{pH}$ range studied; considering that the adsorption processes included cationic exchange, the adsorption of anionic species was hindered, compared to the adsorption of positively charged species. The adsorption of ammoniacal nitrogen was highest at $\mathrm{pH} 3.0$ (for sample TSA). This $\mathrm{pH}$ favors the presence of the ammonium cation, which readily interacted with the organic matter present at high levels in the peat. For both peats, the adsorptive capacity for nitrogen diminished at higher $\mathrm{pH}$, due to deprotonation of the ammonium ion.

Amongst the macronutrients potassium, calcium, and magnesium, calcium showed the greatest adsorption, especially at $\mathrm{pH}$ 6.0. A plausible explanation for this is the smaller diameter of the hydrated calcium ion, compared to the other metal species, enabling it to diffuse more easily amongst the active sites (Van Raij 2011).

\section{Adsorption kinetics}

Although adsorption of the macronutrients was low, the kinetic models were applied in order to improve understanding of the processes involved. The sorption kinetics describes the rate at which the macronutrient is adsorbed by the peat, and can predict the quantity of adsorbate retained in the adsorbent material. Kinetic models are commonly applied to determine the parameters of the limiting step of the process, as well as the rate constant. Selim and Zhang (2013) recently reviewed the kinetic and adsorption models applied to competitive processes involving metals and metalloids in soils and highlighted the importance of using the pseudo-first-order and pseudo-second-order models in order to understand the mechanisms of adsorption. It can be seen from the correlation coefficients $\left(\mathrm{r}^{2}\right)$ presented in Figure 6 and Table 2 that the pseudo-second-order model provided the best fit to the data, with the exception of the adsorption of nitrogen and phosphorus by sample TSA, for which the pseudo-first-order model provided the best fit.
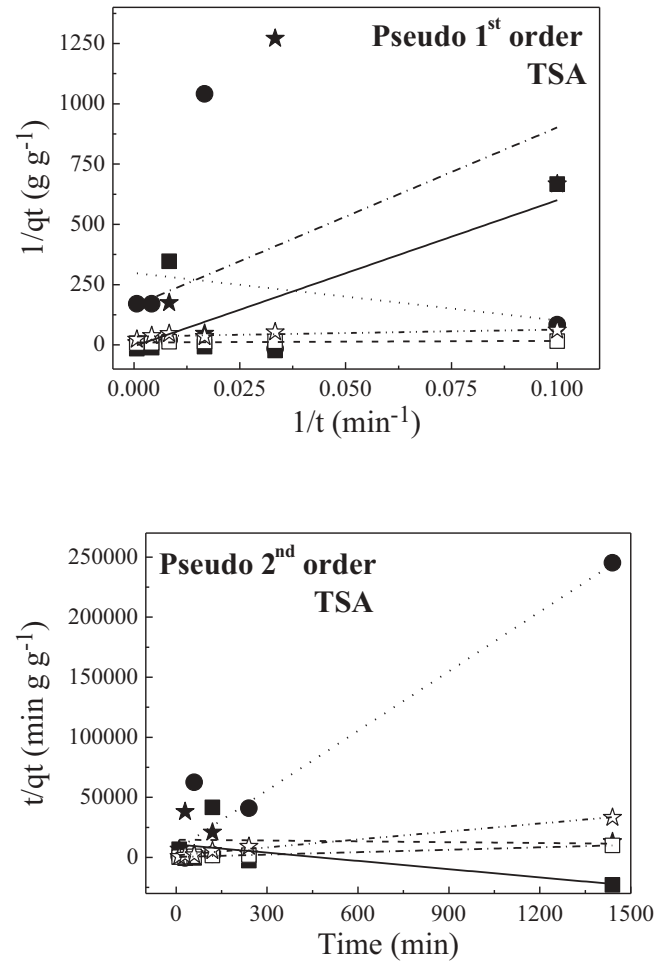
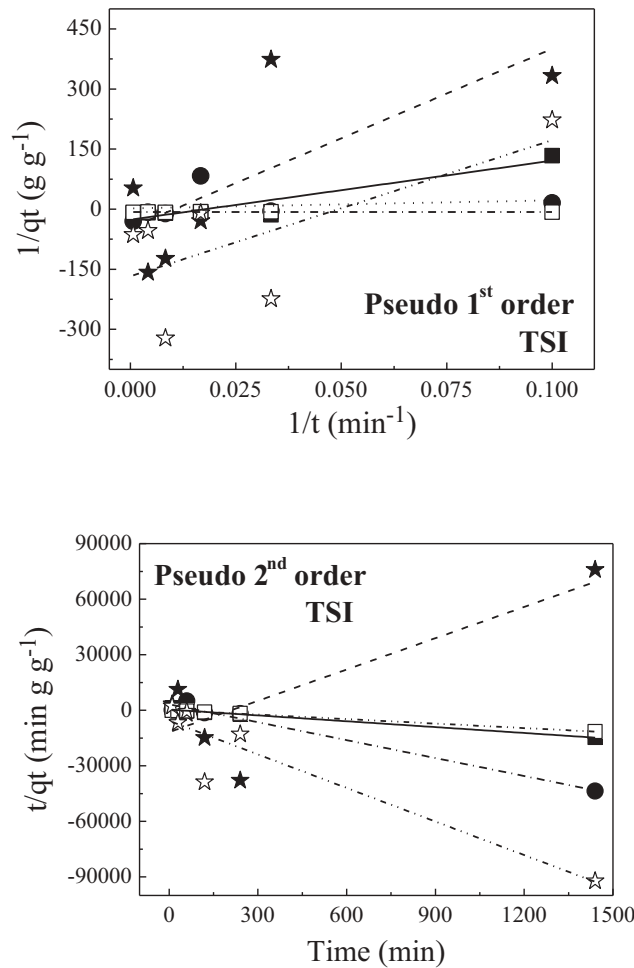

Figure 6. Adsorptive capacities of peat samples TSA and TSI for the macronutrients nitrogen ( $\mathbf{\square})$, calcium ( $\square$ ), potassium (•), phosphorus ( $\square)$, and magnesium (*). 
Table 2. Values of the rate constants, correlation coefficients, and adsorption capacities calculated using the pseudo-first-order and pseudo-second-order models applied to the adsorption of the macronutrients nitrogen, phosphorus, potassium, calcium, and magnesium by peat samples TSA and TSI.

\begin{tabular}{|c|c|c|c|c|c|c|c|}
\hline \multicolumn{2}{|c|}{ TSA $2 \mathrm{~g} ; \mathrm{pH} 6.0$} & \multicolumn{3}{|c|}{ Pseudo-first order } & \multicolumn{3}{|c|}{ Pseudo-second order } \\
\hline \multicolumn{2}{|c|}{ qeq,experimental } & $\begin{array}{c}\mathrm{k}_{1} \\
\left(\mathrm{~h}^{-1}\right)\end{array}$ & $\begin{array}{l}\text { qeq,calculated } \\
\left(\mathrm{mg} \mathrm{g}^{-1}\right)\end{array}$ & $r^{2}$ & $\begin{array}{c}\mathrm{k}_{2} \\
\left(\mathrm{~h}^{-1} \mathrm{~g} \mathrm{mg}^{-1}\right)\end{array}$ & $\begin{array}{c}\text { qeq,calculated } \\
\left(\mathrm{mg} \mathrm{g}^{-1}\right)\end{array}$ & $r^{2}$ \\
\hline $\mathrm{N}$ & 0.06 & $1.13 \times 10^{3}$ & 0.19 & 0.53 & 0.05 & 0.04 & 0.20 \\
\hline P & 0.11 & 45.61 & $6.17 \times 10^{-3}$ & 0.12 & $3.54 \times 10^{-4}$ & 0.44 & -0.24 \\
\hline K & 0.01 & 6.58 & $3.35 \times 10^{-3}$ & -0.21 & 0.35 & $6.05 \times 10^{-3}$ & 0.92 \\
\hline $\mathrm{Ca}$ & 0.14 & 6.56 & 0.09 & 0.32 & 0.93 & 0.15 & 0.99 \\
\hline $\mathrm{Mg}$ & 0.04 & 8.16 & 0.03 & 0.52 & 0.29 & 0.04 & 0.98 \\
\hline $\mathrm{N}$ & 0.10 & 56.04 & 0.04 & 0.86 & 0.28 & 0.09 & 0.99 \\
\hline$P$ & 0.02 & 95.77 & 0.02 & 0.42 & 0.27 & 0.02 & 0.59 \\
\hline $\mathrm{K}$ & 0.03 & 106.13 & 0.53 & -0.21 & 0.32 & 0.03 & 0.97 \\
\hline $\mathrm{Ca}$ & 0.12 & 0.01 & 0.14 & -0.25 & 0.95 & 0.12 & 0.99 \\
\hline $\mathrm{Mg}$ & 0.02 & 20.26 & $5.96 \times 10^{-3}$ & 0.33 & 0.44 & 0.02 & 0.83 \\
\hline
\end{tabular}

Since this model considers the number of available active sites, it appears that the adsorption of nitrogen and phosphorus did not involve those active sites responsible for adsorption of the other (metallic) nutrients. The pseudo-second-order model considers chemical sorption between the adsorbent material and the solutes, involving the sharing and/or exchange of electrons (Ho and McKay 2000). It is therefore likely that the adsorption of magnesium, potassium, and calcium involved chemical sorption.

The values of the rate constants $(\mathrm{k})$ obtained using the pseudo-second-order model indicated that the fastest adsorption was obtained for calcium. Comparison of calcium with the element magnesium, which belongs to the same group in the periodic table, reveals that magnesium possesses a larger ionic radius, so that preferential adsorption will be shown by calcium, which has a smaller hydrated ion radius. Comparing calcium with potassium, which belongs to the same period in the periodic table, an important difference is that potassium possesses an ionic charge of +1 , while that of calcium is +2 so that calcium is, therefore, more strongly attracted to the active sites. The strong competition of calcium, compared to magnesium and potassium, therefore explains the high kinetic rate constant for its adsorption. The adsorptive capacity values calculated from the kinetic model were in line with the experimentally determined values, demonstrating the satisfactory fit of the pseudo-second-order model.

From the data provided in Table 2, it can be seen that calcium was the macronutrient most strongly adsorbed by the peat samples, with the adsorptive capacity being greater for sample TSA, compared to sample TSI. This was due to the different structural chemical characteristics of the peats since sample TSA contained more of the aromatic and phenolic species that act to increase the adsorption capacity.

\section{Conclusions}

Characterization of two different tropical peat samples, using FTIR, TG, and MEV revealed differences in the physic-chemical structures. These differences were reflected in the results with greater adsorptive capacities obtained for sample TSA. The $\mathrm{pH}$ of the medium was an important determinant of the biosorption process, since both the peat and the macronutrients were liable to ionization, forming anionic and cationic species that could interact amongst themselves. From the standpoint of the agricultural application, in addition to providing a valuable source of organic matter to the soil, the previously enriched peats could also be used to deliver calcium and potassium.

\section{Acknowledgments}

This research was supported by the following agencies: Fundação de Amparo à Pesquisa do Estado de São Paulo (FAPESP, 2010/12210-1), Conselho Nacional de Desenvolvimento Científico e Tecnológico (CNPq), and Coordenação 
de Aperfeiçoamento de Pessoal de Nível Superior (CAPES). The authors would like to thank Bruno Barboza Cunha for help with the sampling of peat samples and Renato Grillo for the MEV analysis.

\section{Funding}

This work was supported by the Fundação de Amparo à Pesquisa do Estado de São Paulo [2010/11570-4,2010/12210-1];

\section{References}

Al-Faqih, L., P. D. Johnson, and S. J. Allen. 2008. Evaluation of a new peat-based sorbent for metals capture. Bioresource Technology 99:1394-402. doi:10.1016/j.biortech.2007.01.059.

Campanella, L., M. Tomassetti, and A. Piccolo. 1990. Thermogravimetric and IR analysis of different extracts of humic substances. Thermochimica Acta 170:67-80. doi:10.1016/0040-6031(90)80525-4.

Clesceri, L. S., A. D. Eaton, A. E. Greenberg, A. P. H. Association, A. W. W. Association, and W. E. Federation. 1998. Standard methods for the examination of water and wastewater, 1504. Washington, United States: American Public Health Association.

De Moraes Sa, J. C., C. C. Cerri, R. Lal, W. A. Dick, M. D. C. Piccolo, and B. E. Feigl. 2009. Soil organic carbon and fertility interactions affected by a tillage chronosequence in a Brazilian Oxisol. Soil \& Tillage Research 104:56-64. doi:10.1016/j.still.2008.11.007.

Gadd, G. M. 2009. Biosorption critical review of scientific rationale, environmental importance and significance for pollution treatment. Journal of Chemical Technology and Biotechnology 84:13-28. doi:10.1002/jctb.1999.

Garg, U. K., M. P. Kaur, V. K. Garg, and D. Sud. 2008. Removal of Nickel(II) from aqueous solution by adsorption on agricultural waste biomass using a response surface methodological approach. Bioresource Technology 99:1325-31. doi:10.1016/j.biortech.2007.02.011.

Goveia, D., C. Melo, L. De Oliveira, L. Fraceto, J. Rocha, N. Dias, and A. Rosa. 2013. Adsorption and release of micronutrients by humin extracted from peat samples. Journal of the Brazilian Chemical Society 24:721-30.

Ho, Y., and G. McKay. 2000. The kinetics of sorption of divalent metal ions onto sphagnum moss peat. Water Research 34:735-42. doi:10.1016/S0043-1354(99)00232-8.

Ji, Z. Y., J. S. Yuan, and X. G. Li. 2007. Removal of ammonium from wastewater using calcium form clinoptilolite. Journal of Hazardous Materials 141:483-88. doi:10.1016/j.jhazmat.2006.07.010.

Kamari, A., I. D. Pulford, and J. S. J. Hargreaves. 2011. Binding of heavy metal contaminants onto chitosans - An evaluation for remediation of metal contaminated soil and water. Journal of Environmental Management 92:2675-82. doi:10.1016/j. jenvman.2011.06.005.

Kiehl, E. J. 1985. Fertilizantes organicos, 492. Piracicaba, Brazil: Agronomica Ceres Publisher.

Liu, Y., and J. Wang. 2009. Fundamentals and applications of biosorption isotherms, kinetics and thermodynamics. New York, NY: Nova Science Publishers, Incorporated.

MacNaught, A. D., and A. R. Wilkinson, and Chemistry, I.U.o.P.a.A. 1997. Compendium of chemical terminology: IUPAC recommendations, 1622. Oxford, UK: Blackwell Science Publisher.

Melo, C. D., L. K. De Oliveira, D. Goveia, L. F. Fraceto, and A. H. Rosa. 2014. Enrichment of tropical peat with micronutrients for agricultural applications: Evaluation of adsorption and desorption processes. Journal of the Brazilian Chemical Society 25:36-49.

Moore, P. D. 1989. The ecology of peat-forming processes - A review. International Journal of Coal Geology 12:89-103. doi:10.1016/0166-5162(89)90048-7.

Novoselova, L. Y., and E. E. Sirotkina. 2008. Peat-based sorbents for the purification of contaminated environments: A review. Solid Fuel Chemistry 42:251-62. doi:10.3103/S0361521908040125.

Perminova, I. V., and K. Hatfield. 2005. Remediation chemistry of humic substances: Theory and implications for technology. Use of Humic Substances to Remediate Polluted Environments: from Theory to Practice 52:3-36.

Schnitze, M., and I. Hoffman. 1965. Thermogravimetry of soil humic compounds. Geochimica Et Cosmochimica Acta 29:859-70. doi:10.1016/0016-7037(65)90083-9.

Selim, H. M., and H. Zhang. 2013. Modeling approaches of competitive sorption and transport of trace metals and metalloids in soils: A review. Journal of Environmental Quality 42:640-53. doi:10.2134/jeq2012.0323.

Soares, M. R., J. C. Casagrande, and E. R. Mouta. 2009. Effect of ionic strength and pH on Cadmium adsorption by Brazilian variable-charge soils. Communications in Soil Science and Plant Analysis 40:2132-51. doi:10.1080/ 00103620902960633.

Trompowsky, P. M., V. D. Benites, B. E. Madari, A. S. Pimenta, W. C. Hockaday, and P. G. Hatcher. 2005. Characterization of humic like substances obtained by chemical oxidation of eucalyptus charcoal. Organic Geochemistry 36:1480-89. doi:10.1016/j.orggeochem.2005.08.001.

Van Raij, B. 2011. Fertilidade do solo e manejo de nutrientes. Piracicaba, Brazil: International Plant Nutrition Institute. 
Wahab, M. A., S. Jellali, and N. Jedidi. 2010. Ammonium biosorption onto sawdust: FTIR analysis, kinetics and adsorption isotherms modeling. Bioresource Technology 101:5070-75. doi:10.1016/j.biortech.2010.01.121.

Wu, D. Y., B. H. Zhang, C. J. Li, Z. J. Zhang, and H. N. Kong. 2006. Simultaneous removal of ammonium and phosphate by zeolite synthesized from fly ash as influenced by salt treatment. Journal of Colloid and Interface Science 304:300-06. doi:10.1016/j.jcis.2006.09.011.

Zenteno, M. D. C., R. C. A. De Freitas, R. B. A. Fernandes, M. P. F. Fontes, and C. P. Jordao. 2013. Sorption of Cadmium in some soil amendments for In Situ recovery of contaminated soils. Water Air and Soil Pollution 224:1418. doi:10.1007/s11270-012-1418-8. 